\title{
RESEARCH PAPER \\ MODELING OF ACETOSOLV PULP YIELDS FROM PLANTAIN STALK
}

\author{
B. O. Ogunsile* and M. A. Omotoso \\ Department of Chemistry, University of Ibadan, Ibadan, Nigeria. \\ *Corresponding author: ogunsile@yahoo.com
}

\begin{abstract}
Organosolv pulping processes have been developed as a substitute to the conventional process because of its little or no emission into the environment. Plantain stalk was subjected to acetosolv pulping at atmospheric conditions under the influence of three operating parameters, namely, concentration of acetic acid, $\mathrm{H}_{2} \mathrm{SO}_{4}$ - catalyst and time. The influence of the operational variables on the pulp yield was evaluated using a second - order factorial design. The results showed that the highest pulp yield was $64.14 \%$ which was obtained at the lowest value of the operational variables. The greatest influence on the pulp yield was caused by the concentration of acetic acid while the $\mathrm{H}_{2} \mathrm{SO}_{4}-$ catalyst had the least. The polynomial equation derived predicted the pulp yields with errors less than $6 \%$.
\end{abstract}

Keywords: Acetosolv, pulp yield, operational variables, factorial design

\section{INTRODUCTION}

The increasing demand for pulp and paper products and the relatively high cost of pulp woods coupled with the high rate of deforestation, calls for the utilization of non-wood raw materials such as agricultural by-products, industrial crops and naturally growing plants as alternative or complimentary raw material in the production of pulp and paper (Svenningsen et al., 1999; Waranyou, 2010). These non wood agricultural materials have shorter maturation time and lower lignin contents as com- pared to woods. Hence they consume low pulping chemicals and are relatively easy to be delignified.

It is equally important to develop chemical pulping processes that are environmentally friendly and most appropriate for the processing of non - wood raw materials (Mohieldin, 2014). The conventional alkaline pulping process such as kraft pulping is not suitable for processing non - wood fiber. Alkaline pulping is not environmentally friendly because of the 
sulphur containing compounds it emits into the environment (Pinkerton, 2007). Apart from this, alkaline pulping of non woods produces large amounts of hemi-cellulose, which is difficult to control without inherent loss in the pulp quality (Rousu et al., 2002). On the other hand, the acidic sulphite pulping process is also not desirable and has long been discontinued because of environmental concerns and the poor quality of pulp emanating from it (Bajpai, 2010; Saadia and Ashfaq, 2010).

In recent times, the organosolv pulping process has been developed as a substitute to the conventional process because of its environmental friendliness (Johansson et al., 1987). This pulping process utilized organic solvents such as alcohol or organic acids as the pulping liquor in the delignification of plant fiber (Ligero et al., 2005; Ferrer et al., 2013; Wildschut et al., 2013; Snelders et al., 2014). High temperatures are usually employed in the use of organic alcohol such as methanol and ethanol, while organic acids such as acetic acid (acetosolv) can be utilized at relatively low temperature and atmospheric pressure (Jahan et al., 2007). The acid can easily be recovered by distillation and subsequently recycled. In addition, the cellulose, hemicellulose and lignin contents can be separated by degradation in the aqueous acetic acid (Muurinen, 2000; Waranyou 2010).

Plantain stalk is available in most major markets in Nigeria as an agricultural waste that can be employed as non wood raw material in the pulp and paper industry. Although, the pulp and paper potentiality of the stalk under the soda pulping process has been considered (Ogunsile et al., 2006), the acetosolv pulping process has not been employed or modeled. The present study was aimed at modeling the pulp yields of acetosolv pulping of plantain stalk under three operational parameters, using the second - order factorial design.

\section{MATERIALS AND METHODS Material preparation}

The plantain stalk used for the study was ob- tained from the plantain market in Sabo Ilesha Osun state Nigeria. The stalk was cut into pieces, washed with water and then sun dried. The plantain stalk was ground and sieved into about 2- $4 \mathrm{~mm}$. It was kept in a sealed polythene bag at room temperature.

\section{Characterization of experimental materials}

The composition of the plantain stalk sample was determined to be $40.8 \%$ cellulose, $8.5 \%$ lignin, $11.8 \%$ ash and $2.3 \%$ alcohol-benzene extractives as described in our previous work (Omotoso and Ogunsile, 2009).

\section{The pulping process}

Acetic acid cooking liquor was prepared from a standard concentrated solution of ethanoic acid by serial dilution with de-ionized water. About $2.5 \mathrm{~g}$ stalk fiber was place in a $250 \mathrm{ml}$ flask with the appropriate amount of acetic acid (60$90 \%$ by weight), as the pulping liquor and $\mathrm{H}_{2} \mathrm{SO}_{4}(0.5-1.5 \%$ by weight), as the catalyst. The solvent / plantain stalk fiber ratio was 20:1 wt/wt. The flask was fitted to a condenser and the mixture was heated slowly to about $100{ }^{\circ} \mathrm{C}$ and refluxed for the next 60 to 180 minutes. At the end of the pulping time, the resulting pulp was thoroughly washed with tap water, drained and dried.

\section{Pulp yields}

The pulp yield was determined gravimetrically after drying at $102{ }^{\circ} \mathrm{C}$ to a constant weight in the oven as follows:

Pulp yield $(\%)=100 *$ Oven dry weight of pulp (g) / 2.5 (g)

\section{Experimental design}

(The central composite factorial design)

The central composite factorial design was employed to evaluate and quantify the effect of the operational variables on the pulp yields. The effect of the variables were quantified more precisely by choosing part of the experimental results and grouping them to form a first order full factorial design, with variables at two levels $\left(2^{3}\right)$. Using this design, some of the experimental data were fitted to a first order polyno- 
mial regression equation as implemented in the "SPSS" statistical package. Individual and second order interaction influences over the response surface of the independent variables were evaluated (Aknazarova and Kafarov, 1982; Khuri and Cornell, 1987).

The mathematical model was:

$Y=a_{0}+a_{1} X_{1}+a_{2} X_{2}+a_{3} X_{3}+a_{12} X_{1} X_{2}+a_{13} X_{1}$ $X_{3}+a_{23} X_{2} X_{3}+a_{11} X_{1} X_{1}+a_{22} X_{2} X_{2}+a_{33} X_{3} X_{3}$

The response variable $\mathrm{Y}$ represents the pulp yield. The independent variables, $X_{1}, X_{2}$ and $X_{3}$ correspond to concentration of acetic acid (60 to $90 \%$ by weight), $\mathrm{H}_{2} \mathrm{SO}_{4}$ - catalyst concentration ( 0.5 to $1.5 \%$ by weight) and time (60 to 180 minutes) respectively. The values of the independent variables were normalized from -1 to +1 by using the equation:

$X_{n}=2(\bar{\chi}-X) /\left(X_{\max }-X_{\min }\right)$

Where:

$X_{n}$ is the normalized value of acetic acid, $\mathrm{H}_{2} \mathrm{SO}_{4}$-catalyst and time.

$X$ is the absolute experimental value of the variable.

$\bar{\chi}$ is the mean of all the experimental values for the variable in question

$X_{m a s}$ and $X_{m i n}$ are the maximum and minimum values respectively of such a variable.

The central point of the design corresponds to the following reaction conditions:

Concentration of acetic acid $=75 \%$

$\mathrm{H}_{2} \mathrm{SO}_{4}-$ catalyst $=1.0 \%$

Time $=120$ minutes,

All normalized independent variables for the central points of the design were designated zero.
Modeling of acetosolv pulp yields ...

\section{RESULTS AND DISCUSSION}

Variation in pulp yields

The result of the pulp yields and operational variables is shown in Table 1. It was observed that the pulp yield ranges from $45.79 \%$ to $64.14 \%$. Values of the acetosolv pulp yields varied from plant to plant under differently or similarly related reaction conditions. The values of the pulp yield obtained in this study (45.79 \% to $64.14 \%$ ) were higher than values of $28.3 \%$ to $33.8 \%$ reported in our previous study where soda liquor was used to pulp the same plant material (Ogunsile et al., 2006). This showed that acetic acid would be preferred to soda pulping liquor especially when high pulp yield is desired.

The pulp yields were similar to $52.6 \%$ obtained from Miscanthus sinensis bark by the acetosolv process (Ligero et al. 2005), $46.3 \%$ for depithed cardoon (Cynara cardunculus) stalks (Ligero et al. 2007), $46.56 \%$ for empty fruit bunches from palm oil industry (Ferrer et al. 2013) and an average of about $50 \%$ for four species of pine (Witayakran et al. 2014). However, the use of phosphinic acid and alkaline pre-extraction of the fiber resulted in a higher range of yields from $43.3 \%$ to $79.4 \%$ reported for birch wood chips (Kangas et al., 2015).

Table 1: Effects of process variables on pulp yields

\begin{tabular}{cccc}
\hline $\begin{array}{c}\mathrm{CH}_{3} \mathbf{C O O H} \\
\text { (weight \%) }\end{array}$ & $\begin{array}{c}\mathbf{H}_{2} \mathbf{S O}_{4} \\
\text { (weight } \\
\text { \%) }\end{array}$ & $\begin{array}{c}\text { Time } \\
\text { (min.) }\end{array}$ & $\begin{array}{c}\text { Pulp yield } \\
(\%)\end{array}$ \\
\hline 90 & 1.5 & 180 & 47.04 \\
90 & 1.5 & 60 & 49.25 \\
90 & 0.5 & 180 & 45.79 \\
90 & 0.5 & 60 & 57.94 \\
60 & 1.5 & 180 & 53.2 \\
60 & 1.5 & 60 & 56.01 \\
60 & 0.5 & 180 & 57.51 \\
60 & 0.5 & 60 & 64.14 \\
75 & 1.0 & 60 & 53.01 \\
75 & 1.0 & 120 & 52.31 \\
75 & 1.0 & 180 & 48.73 \\
\hline
\end{tabular}




\section{Ogunsile and Omotoso}

As seen in Table 1, pulp yields are affected by the concentration of the pulping liquor and the duration of the pulping process. Generally, pulping carried out at high concentration of acetic acid is associated with relatively low pulp yields. Low pulp yields are also obtained at long periods of pulping (180 minutes) as compared to short durations (60 minutes). Although high concentration of pulping liquor increases the dissolution and removal of lignin content, it also initiates the degradation of the carbohydrate and cellulose materials, leading to a low pulp yield. The effect is more pronounced the longer the pulping time. Thus, a compromise must be reached between concentration of pulping liquor and pulping time such that optimum but tolerable pulp yields are obtained. Optimization of process variables is therefore highly necessary for maximum lignin removal and optimum pulp yields (Ogunsile and Uba, 2012; Brahim et al. 2017).

Optimum concentration of acetic acid as a pulping liquor varied from plant to plant and the reaction conditions employed. An acetic acid concentration of $93.25 \%$ was reported for Miscanthus sinensis bark; $\geq 71.3 \%$ for cardoon bark (Cynara cardunculus); $86.25 \%$ for empty fruit bunches from the palm oil industry and 95 $\%$ for four pine species including Pinus kesiya, Pinus merkusii, Pinus caribaea, and Pinus oocarpa (Ligero et al., 2005, 2007; Ferrer et al., 2013; Witayakran et al., 2014). These values, however, depend on the duration of pulping, temperature, plant materials and the objective of pulping. Generally high concentrations of pulping liquor are usually employed especially for producing bleachable pulps. This reduces the bleaching loads and chemical required in the bleaching plants.

\section{Central composite design}

The absolute and normalized values of independent variables with the pulp yields are presented in Table 2. Experiments 1-15 allowed the calculation of different parameters in the regression equations $a_{i}$ and $a_{i j}$. These were subsequently subjected to a $\mathrm{T}$ - test to check their

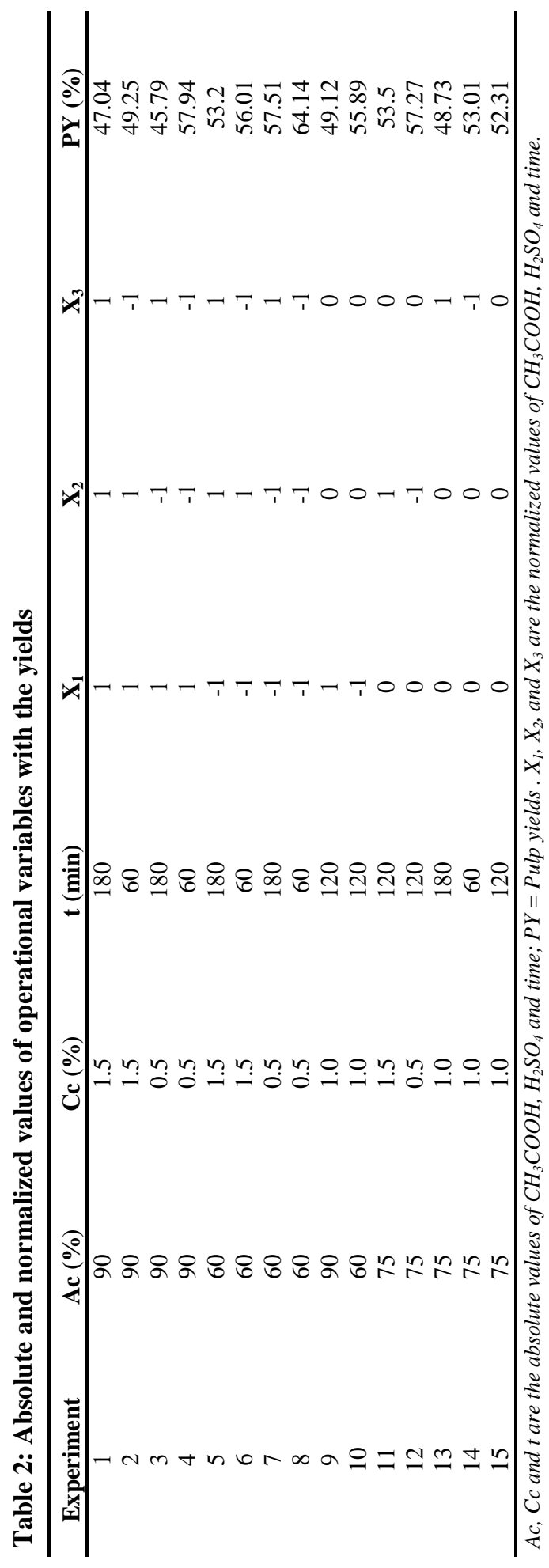

Journal of Science and Technology @ KNUST April 2017 
Modeling of acetosolv pulp yields ...

significance at $95 \%$ confidence level.

The coefficients of the model equation and the statistical parameters establishing its validity are summarized in Table 3.

Table 3: Significant and non-significant regression parameters

\begin{tabular}{cc}
\hline Factor & Yield \\
\hline $\mathrm{a}_{0}$ & 52.41 \\
$\mathrm{a}_{1}$ & -3.76 \\
$\mathrm{a}_{2}$ & -2.37 \\
$\mathrm{a}_{3}$ & -2.81 \\
$\mathrm{a}_{12}$ & $(-0.625)$ \\
$\mathrm{a}_{13}$ & $(-0.615)$ \\
$\mathrm{a}_{23}$ & 1.72 \\
$\mathrm{a}_{11}$ & $(-0.071)$ \\
$\mathrm{a}_{22}$ & 2.95 \\
$\mathrm{a}_{33}$ & $(-1.56)$ \\
$\mathrm{R}^{2}$ & 0.98 \\
$\mathrm{R}^{2}$ adj. & 0.944 \\
$\mathrm{~F}$ & 27.3 \\
\hline
\end{tabular}

The non-significant parameters at 0.05 levels are in parenthesis

The pulp yield was related to the independent variables through the equation:

Yield $=52.41-3.76 X_{1}-2.37 X_{2}-2.81 X_{3}+$ $2.95 X_{2} X_{2}+1.72 X_{2} X_{3}$

The values of $R, R^{2}$ and adjusted $R^{2}$ were 0.99 , 0.98 and 0.944 respectively. The different factor values of $a_{0}, a_{1}, a_{2}, \ldots$ the fitting parameters by which the effects of each of the independent variables on the dependent variable (experimental results) can be determined and compared (Ligero, et al., 2007; Ogunsile and German, 2010). All calculations were performed with a statistics module of SPSS.

Values calculated from the polynomial equation above were plotted with the experimental results for the different response variables as shown in Fig. 1. The results showed good correlation between the experimental values and those predicted by the models.

Equation 3 allows the estimation of the variation of the yield with changes in each independent variable over the range considered while the other two remain constant. Non-significant parameters were dropped to obtain simpler equations. The equation showed that each of the operation variables, namely $\mathrm{CH}_{3} \mathrm{COOH}$, $\mathrm{H}_{2} \mathrm{SO}_{4}$ - catalyst and time had significant influence at $95 \%$ confidence level on the pulp yield as apparent from the values of $\mathrm{a}_{1}, \mathrm{a}_{2}$ and $\mathrm{a}_{3}$, and Figs 1, 2 and 3 respectively. Fig. 1 represents the behaviour of the pulp yield with respect to the variations in time and $\mathrm{CH}_{3} \mathrm{COOH}$ at a high constant $\mathrm{H}_{2} \mathrm{SO}_{4}-$ catalyst. Figure 2 is the pulp yield behaviour according to variation in the two acids, while figure 3 describes the yield with variation in time and $\mathrm{H}_{2} \mathrm{SO}_{4}$ - catalyst. There were also significant interaction between $\mathrm{H}_{2} \mathrm{SO}_{4}$-catalyst and time $\left(\mathrm{a}_{23}\right)$ on one hand, and the quadratic effect caused by the $\mathrm{H}_{2} \mathrm{SO}_{4}-$

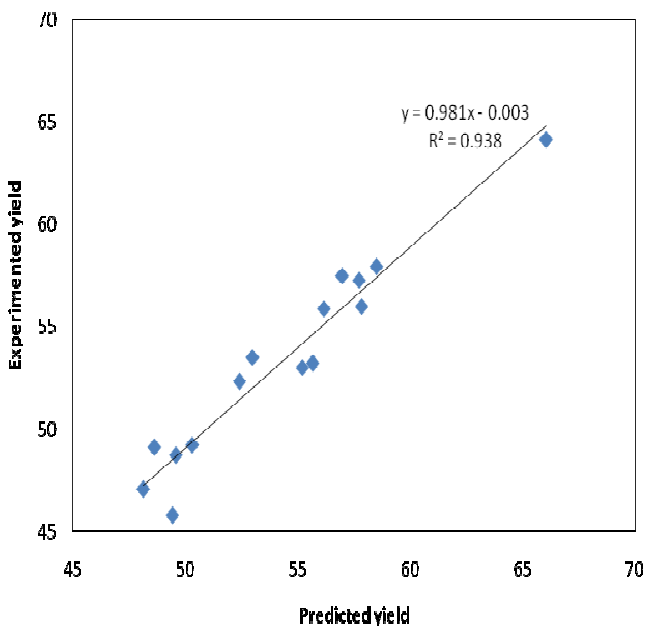

Fig. 1: Correlation between experimented and predicted values of pulp yield 
6

\section{Ogunsile and Omotoso}

Yield

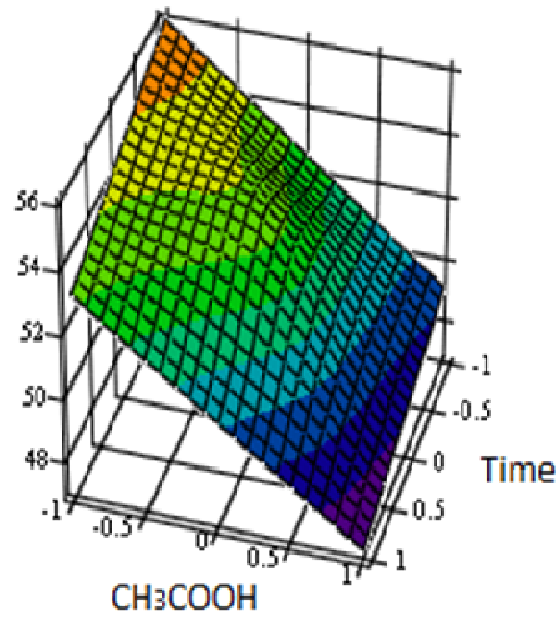

(Time, $\mathrm{CH} 3 \mathrm{COOH}$, Yield)

Fig. 2: Variation of the pulp yield with Time and $\mathrm{CH}_{3} \mathrm{COOH}$, at a constant concentration of $\mathrm{H}_{2} \mathrm{SO}_{4}$ - catalyst

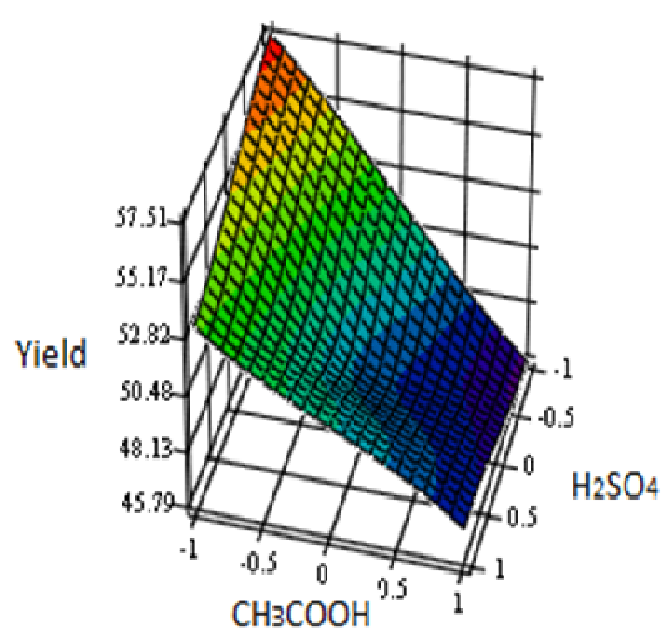

(H2SO4, $\mathrm{CH} 3 \mathrm{COOH}$, Yield)

Fig. 3: Variation of the pulp yield with $\mathrm{H}_{2} \mathrm{SO}_{4}$ - catalyst and $\mathrm{CH}_{3} \mathrm{COOH}$ at a constant Time

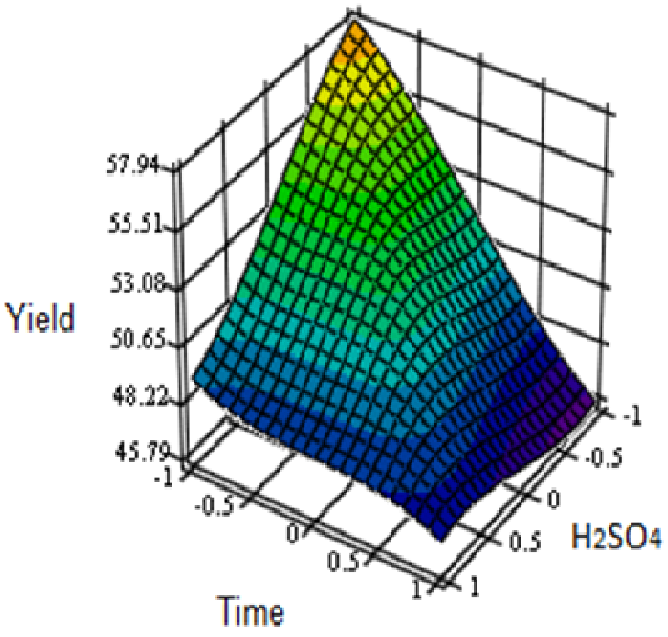

(H2SO4, Time, Yield)

Fig. 4: Variation of the pulp yield with $\mathrm{H}_{2} \mathrm{SO}_{4}$ - catalyst and Time at a constant concentration of $\mathrm{CH}_{3} \mathrm{COOH}$

catalyst $\left(\mathrm{a}_{22}\right)$.

According to equation 2, the lowest pulp yield $(48.14 \%)$ was obtained at large values of the three process variables (i.e. +1 for all). If yield similar to chemical pulp is desired, then all the process variables must be at normalized values of +1 . However, this lowest yield can be raised to $55.66 \%$ by using a low concentration of acetic acid (-1 normalized value), which will also bring a reduction in the amount of chemicals consumed. The highest predictable yield was $66.02 \%$, which occurs at low values of the process variables (-1 for all). A similar result was reported in the pulping olive tree trimming with ethanol where the highest pulp yield was obtained at low values of operational variables and vice versa. The maximum variation in the highest pulp yield was caused by changes in acetic acid concentration (a change of 7.52 units). This was reflected by the large negative slopes observed in Figs 1 and 2. The minimum variation in the highest pulp yield was caused 
by changes in $\mathrm{H}_{2} \mathrm{SO}_{4}$ - catalyst concentrations (a change of 1.3 units) while the effect of time ( 2.18 units) lie in between as observed by the response graph of Fig. 3.

\section{CONCLUSIONS}

The study revealed the acetosolv pulping potentials of plantain stalk at atmospheric conditions. The pulp yields were successfully modeled using the second-order factorial design with errors less than $6 \%$. The optimum pulp yield was obtained at the lowest values of the operational variables, and was predicted to be 66.02 $\%$ compared to the experimented yield of 64.14 $\%$. The maximum variation in the highest pulp yield was caused by changes in the concentration of acetic acid. This was followed by changes in time or duration of pulping, while changes in the concentration of $\mathrm{H}_{2} \mathrm{SO}_{4}$ - catalyst was the least.

\section{ACKNOWLEDGEMENT}

The authors wish to acknowledge the Department of Chemical Sciences, Redeemers University for providing most of the facilities for this research work and the University of Ibadan, for granting the sabbatical placement at Redeemers University.

\section{REFERENCES}

Aknazarova, S. and Kafarov, V. (1982). Experiment Optimization in Chemistry and Chemical Engineering. Mir Publishers, Moscow.

Bajpai, P. (2010). Environmentally-friendly production of pulp and paper. John Wiley \& Sons, Inc., Hoboken, New Jersey, USA.

Brahim, M., Boussetta, N., Grimi, N., Vorobiev, E., Zieger-Devin, I. and Brosse, N. (2017). Pretreatment optimization from rapeseed straw and lignin characterization. Industrial Crops and Products, 95: 643-650

Ferrer, A., Vega, A., Rodriguez, A. and Jimenez, L. (2013). Acetosolv pulping for the fractionation of empty fruit bunches from
Modeling of acetosolv pulp yields ... 7 palm oil industry. Bioresource Technology, 132: 115-120.

Jahan, M. S., Chowdhury, D. A. N. and Islam, M. K. (2007). Atmospheric formic acid pulping and TCF bleaching of dhaincha (Sesbania aculeata), kash (Saccharum spontaneum) and banana stem (Musa Cavendish). Industrial Crops and Products, 26(4): 324331.

Johansson, A., Aaltonen, O. and Ylinen, P. (1987). Organosolv pulping - methods and pulp properties. Biomass, 13(1): 45-65

Ligero, P, Vega, A. and Bao, M. (2005). Acetosolv delignification of Miscanthus sinensis bark. Influence of process variables. Industrial Crops and Products, 21(3): 235-240.

Ligero, P., Villaverde, J. J., Vega, A. and Bao, M. (2007). Acetosolv delignification of depithed cardoon (Cynara cardunculus) stalks. Industrial Crops and Products 25: 294-300

Kangas, H., Hakala, T. K., Tamminen, T., Määttänen, M., Rovio, S., Liitiä, T. and Poppius-Levlin, K. (2015). Optimisation of acetic acid lignofibre organosolv process, BioResources, 10(2): 2699-2718

Khuri, A. I. and Cornell, J. A. (1987). Response surfaces: designs and analyses. M. Dekker, University of Michigan, NY.

Mohieldin, S. D. (2014). Pretreatment approaches in non-wood plants for pulp and paper production: A review. Journal of Forest Products and Industries, 3(2): 84-88

Muurinen, E. (2000). Organosolv pulping: A review and distillation study related to peroxyacid pulping. Department of Process Engineering, University of Oulu, FIN-90014 University of Oulu, Finland.

Ogunsile, B. O., Omotoso, M. A. and Onilude, M. A. (2006). Comparative physicochemical 
properties and soda pulps from the mid-rib, pseudostem and stalk of Musa paradisiaca. Journal of Biological Science, 6 (6): 1047 1052.

Ogunsile, B. O. and German C. Q. (2010). Modelling of soda - ethanol pulps from Carpolobia lutea. BioResources, 5(4):24172430 .

Ogunsile, B.O. and Uba, F. I. (2012). Optimization of process variables for the soda pulping of Carpolobia lutea (Polygalaceae) G. Don. Journal of the Korean Chemical Society, 6 (2): 1-7.

Omotoso, M. A. and Ogunsile, B. O. (2009). Fiber and chemical properties of some Nigerian grown Musa species for pulp production. Asian Journal of Material Science, 1(1): 1421.

Pinkerton, J. E. (2007). Sulfur dioxide and nitrogen oxides emissions from U.S. pulp and paper mills, 1980 - 2005. Journal of the Air and Waste Management Association. 57(8): 901-906.

Rousu, P., Rousu' P. and Anttila, J. (2002). Sustainable pulp production from agricultural waste. Resources Conservation and Recycling, 35 (1-2): 85-103.

Saadia A. and Ashfaq, A. (2010). Environmental management in pulp and paper industry. Journal of Industrial Pollution Control, 26 (1): 71-77.
Snelders, J., Dornez, E., Benjelloun-Mlayah, B. Huijgen, W. J. J., de Wild, P.J., Gosselink, R. J. A., Gerritsma, J. and Courtin, C. M. (2014). Biorefining of wheat straw using an acetic and formic acid based organosolv fractionation process. Bioresource Technology, 156: $275-282$.

Svenningsen, N., Visvanathan, C., Malinen, R. and Patankar, M. (1999). Cleaner product in the pulp and paper industry: Technology fact sheets. Asian Institute of Technology and the United Nations Environment Programme (UNEP). Pathumtani, Thailand.

Waranyou, S. (2010). The environmentally benign pulping process of non-wood fibers. Suranaree Journal of Science and Technology. 17 (2): 105-123.

Wildschut, J., Smit, A. T., Reith, J. H. and Huijgen, W. J. J. (2013). Ethanol-based organosolv fractionation of wheat straw for the production of lignin and enzymatically digestible cellulose. Bioresource Technology, 135: 58-66.

Witayakran, S., Thinnapatanukul, T., Plumpanya, S. and Anaphanuruk, W. (2014). Acetosolv pulp properties of four pine species. Proceedings of the 52nd Kasetsart University Annual Conference, Kasetsart University, Thailand. Science, Natural Resources and Environment, 4:360-366. 